\title{
Neurogenic hypertension associated with an excessively high excretion rate of catecholamine metabolites
}

\author{
CHRISTIAN FUNCK-BRENTANO, „ JEAN-YVES PAGNY, JOËL MENARD \\ From Service d'Hypertension Artérielle et de Médecine Interne, Hôpital Broussais, Paris, France
}

SUMMARY A 60 year old hypertensive patient suffered several cerebral infarctions. A phaeochromocytoma was suspected because the excretion rates of vanillylmandelic acid and its methoxy derivatives were raised and the patient had hypertensive crises. No tumour was found, however, by ${ }^{131 \mathrm{~m}}$ I-iodobenzylguanidine scintigraphy and computed tomography of the abdomen. Moreover, the enhanced orthostatic plasma catecholamine response suggested that the high excretion rates of catecholamine metabolites were more likely to be caused by the syndrome of raised catecholamines after cerebrovascular accidents than a phaeochromocytoma.

A phaeochromocytoma should not be diagnosed within several months of cerebral infarction without first excluding the possibility of a hyperadrenergic state induced by cerebral infarction.

Hypertension associated with increased excretion of catecholamines has been described in several conditions that simulate phaeochromocytoma. ${ }^{2} \mathrm{We}$ describe a hypertensive patient who had several cerebral infarctions and excessively high excretion rates of catecholamine metabolites that persisted for several months. Phaeochromocytoma, whether adrenal or ectopic, was not demonstrated despite the use of specific and sensitive diagnostic techniques. An excessive increase in plasma catecholamine concentration in response to standing up suggested a non-tumoral pattern that was consistent with a neurogenic hyperadrenergic state.

\section{Case report}

A 60 year old man was referred to our hospital on 2 December 1984 with severe resistant hypertension and a high excretion rate of catecholamine metabolites. He had a two year history of asymptomatic untreated hypertension with no other relevant medical or surgical history. On 4 October 1984 right facial palsy with dysarthria developed suddenly and he was admitted to another hospital. Fluctuating

^Present address: Dr Christian Funck-Brentano, Department of Pharmacology-Room AA 3228, Medical Center North, Vanderbilt University, Nashville, TN 37232, USA.

Reprints will not be available from the authors. high blood pressure was found. Examination disclosed a mild right hemiparesia without sensory loss. Clinical examination was otherwise normal. Standard laboratory values were normal. An electrocardiogram disclosed typical signs of left ventricular hypertrophy and normal sinus rhythm. A chest radiograph showed mild cardiomegaly but no mediastinal tumour. Intravenous digitised cervical angiography showed major atherosclerotic lesions of both vertebral arteries without obstruction. The urinary excretion rate of catecholamine metabolites was measured 10 days after admission. ${ }^{3}$ It gave the following results: vanillylmandelic acid $6.21 \mathrm{mg}(31.3$ $\mu \mathrm{mol}) / 24 \mathrm{~h}$ (normal $<8 \mathrm{mg}(40.4 \mu \mathrm{mol}) / 24 \mathrm{~h}$ ); metanephrine and normetanephrine $1407 \mu \mathrm{g}$ $($ normal $<700 \mu \mathrm{g}) / 24 \mathrm{~h}$; normetanephrine $972 \mu \mathrm{g}$ $(5 \cdot 3 \mu \mathrm{mol}) / 24 \mathrm{~h}$.

Blood pressure remained unstable despite the administration of several antihypertensive drugs (figure). Excretion rates of catecholamine metabolites remained raised and concentrations of normetanephrine predominated over those of metanephrine. The excretion rate of vanillylmandelic acid reached $11.8 \mathrm{mg} / 24 \mathrm{~h}$ $(59.5 \mu \mathrm{mol} / 24 \mathrm{~h})$ on 16 November 1984 . On 28 November the patient had a left hemiparesis that spared his face.

At admission the patient was drowsy. Supine blood pressure was $214 / 108 \mathrm{~mm} \mathrm{Hg}$ and the pulse 


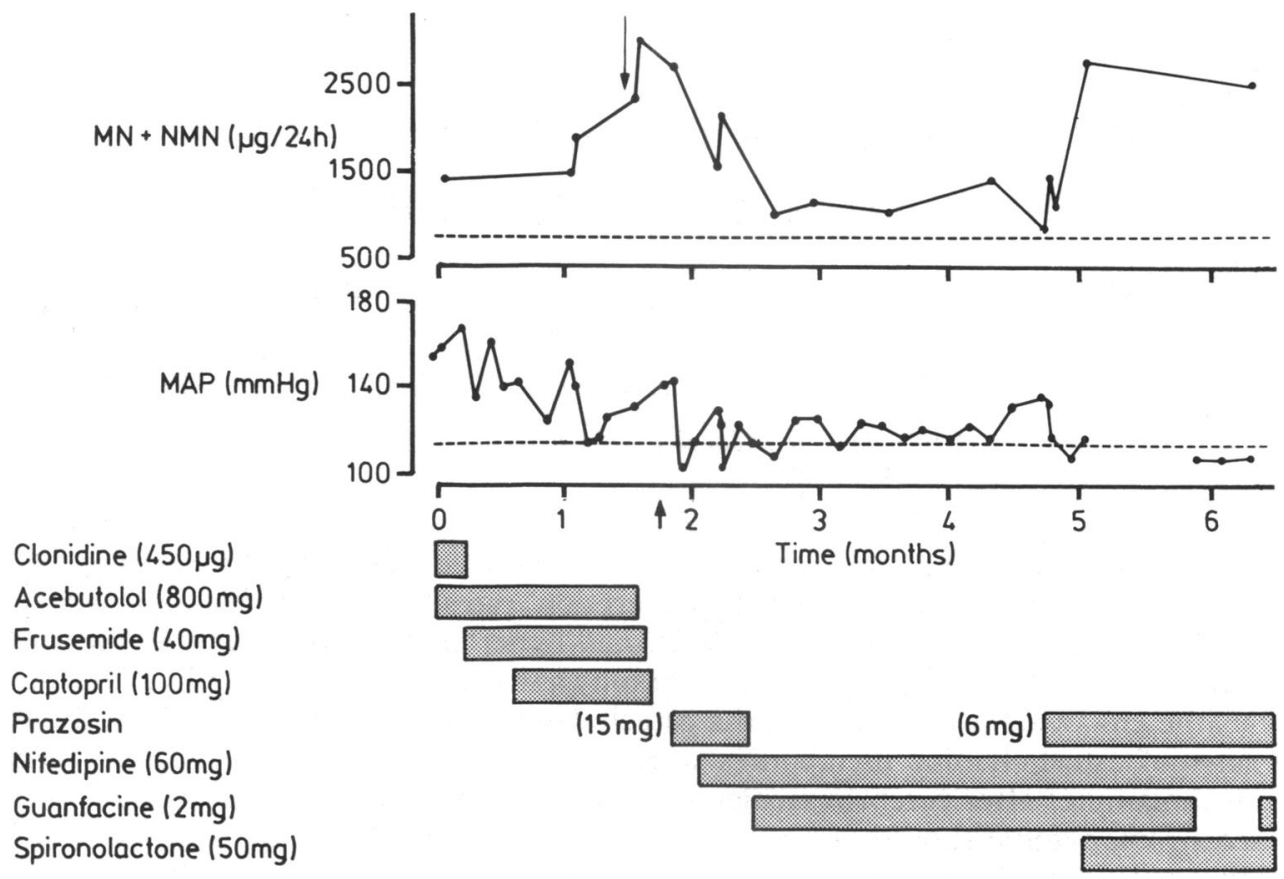

Figure Clinical course of the patient. Broken lines represent the upper limit for normal values. The small arrow indicates the time the patient had his second cerebral infarction. The large arrow indicates the time of admission to our hospital. Daily dosage of antihypertensive drugs is indicated. MAP, mean arterial pressure. Values are the means of two or three daily supine blood pressure measurements; $M N+N M N$, metanephrine + normetanephrine. MN $1 \mu \mathrm{mol}=197 \cdot 23 \mu \mathrm{g} ; \mathrm{NMN} 1 \mu \mathrm{mol}=183 \cdot 20 \mu \mathrm{g}$.

rate was 66 beats/minute. He did not have a history of headache, excessive sweating, or palpitation. Neurological examination revealed a mild left sided pure motor deficit sparing the face, fluctuating consciousness, and frequent yawns. Clinical examination was otherwise normal. Lumbar puncture yielded a sample of normal cerebrospinal fluid. A cerebral computed tomogram revealed multiple areas of reduced density. The blood pressure continued to fluctuate, with supine systolic pressure ranging from 140 to $250 \mathrm{~mm} \mathrm{Hg}$. Blood pressure peaks were not accompanied by headache, sweating, or tachycardia. Irrespective of the treatment the patient was taking, there was a mean drop of systolic and diastolic blood pressure of 25 and $10 \mathrm{~mm} \mathrm{Hg}$ respectively and a concomitant $30 \%$ average increase of heart rate when he stood up. Micturition did not induce headache, sweating, tachycardia, or variation in blood pressure. The results of intravenous pyelography were normal. A computed tomogram of the adrenal glands did not show a tumour. Whole body $131 \mathrm{~m} I$-iodobenzylguanidine scintigraphy, which included the head, did not show any abnormal uptake. Urinary bladder uptake revealed no important abnormality.
The excretion rate of catecholamine metabolites (metanephrine, normetanephrine, vanillylmandelic acid) reached a peak three days after the occurrence of the left hemiparesis and remained raised during the next three months. Then a second rise occurred (figure). The specificity of the urinary determinations was borne out by the results of high performance liquid chromatography. An oral dose of $1 \mathrm{mg}$ of prazosin produced a maximum drop of $4 \%$ in arterial blood pressure during a seven hour follow up.

Four and a half months after admission, 10 days after the withdrawal of guanfacine and while the patient was taking prazosin, nifedipine, and spironolactone, we measured plasma catecholamine concentrations while he was supine and after standing up. ${ }^{4}$ The following results were obtained: noradrenaline $5661 \mathrm{pg} / \mathrm{ml}(33.5 \mathrm{pmol} / \mathrm{ml})$ supine and $11796 \mathrm{pg} / \mathrm{ml}(69.7 \mathrm{pmol} / \mathrm{ml})$ after standing for five minutes (normal supine $<355 \mathrm{pg} / \mathrm{ml}$ $(2.1 \mathrm{pmol} / \mathrm{ml}))$; adrenaline $162 \mathrm{pg} / \mathrm{ml}(0.88 \mathrm{pmol} / \mathrm{ml})$ supine and $287 \mathrm{pg} / \mathrm{ml}(1.57 \mathrm{pmol} / \mathrm{ml})$ after standing for five minutes (normal supine $<85 \mathrm{pg} / 1$ $(0.46 \mathrm{pmol} / \mathrm{ml}))$. Neurological examination was consistent with a so-called pseudobulbar palsy. 


\section{Discussion}

This case emphasises the difficulty in distinguishing between phaeochromocytoma and cerebrovascular accidents causing raised concentrations of catecholamines. In hypertensive patients with raised excretion rates of catecholamine metabolites, the diagnosis of true (tumoral) phaeochromocytoma is suggested by several features. These are the triad of headache, sweating attacks, and palpitation. When this triad is absent, the probability of phaeochromocytoma is $<1$ in $1000 .^{5}$ A prolonged $(75 \mathrm{~h})$ fall in blood pressure after the administration of prazosin is also suggestive of phaeochromocytoma. ${ }^{6}$ Crises precipitated by micturition have been described in patients with bladder phaeochromocytoma. $^{7}$

Computed tomography can detect small tumours and is particularly useful for the diagnosis of ectopic tumours when these are indicated by scintigraphy or venous concentrations of catecholamines. The diagnosis and localisation of adrenal and extra-adrenal phaeochromocytomas has been improved by the use of $131 \mathrm{~m}$ I-iodobenzylguanidine scintigraphy, which has a sensitivity of $89 \%$ and a specificity of $95 \%$ for the diagnosis of true phaeochromocytomas. ${ }^{8}$

Plasma and urine catecholamine concentrations also help to distinguish between true phaeochromocytomas and the syndrome of raised catecholamines. Raised urinary concentrations of adrenaline usually indicate an intra-adrenal tumour; however, there are reports of false negative results. ${ }^{8}$ It has been suggested that a plasma adrenaline concentration of $<200 \mathrm{pg} / \mathrm{ml}(1 \cdot 1 \mathrm{nmol} / \mathrm{l})$ associated with a noradrenaline plasma concentration less than twice the upper limit of normal indicates a nontumoral cause for the hyperadrenergic state. ${ }^{9}$ The most important features in patients with phaeochromocytoma are the lack of an increase in plasma catecholamines in response to standing ${ }^{10}$ and the lack of a decrease in plasma catecholamine concentrations after pentolinium ${ }^{9}$ or clonidine. ${ }^{11}$ When ${ }^{131 \mathrm{~m}} \mathrm{I}$-iodobenzylguanidine scintigraphy is negative but plasma catecholamine concentrations indicate the presence of a phaeochromocytoma, selective venous sampling of catecholamines is invaluable in determining the sources of the excess catecholamines. ${ }^{12}$ This technique requires considerable radiological skill and expert assay facilities, however.

Cerebral infarction can increase total catecholamine concentrations in the peripheral venous plasma of hypertensive patients, ${ }^{13}$ and catecholamine urinary excretion rates. ${ }^{14}$ Stoica et al found that urinary noradrenaline excretion increased in the first week after cerebral infarction in 46 patients, whereas it was normal thereafter. The excretion rate of vanillylmandelic acid was normal during the first month. ${ }^{14}$ We believe that the clini- cal, biological, and radiological picture in our patient rules out the presence of a phaeochromocytoma and suggests a hyperadrenergic state induced by cerebral infarction.

In hypertensive patients with high catecholamine excretion rates after cerebral infarction, $131 \mathrm{~m}$ I-iodobenzylguanidine scintigraphy and plasma catecholamine response to standing or suppression tests are most useful in distinguishing between a true phaeochromocytoma and the syndrome of raised catecholamines. Because blood pressure control was only achieved in our patient after administration of guanfacine and prazosin we suggest that hypertensive patients with high excretion rates of catecholamines after cerebral infarction should be treated with peripheral $\alpha_{1}$ blocking agents and/or centrally acting $\alpha_{2}$ agonists.

We thank Dr Etienne Comoy for measuring the plasma catecholamine concentrations.

\section{References}

1 Kuchel O. Pseudopheochromocytoma. Hypertension 1985;7:151-8.

2 Mazey RM, Kotchen TA, Ernst CB. A syndrome resembling pheochromocytoma following a stroke. Report of a case. JAMA 1974;230:575-7.

3 Anton AH, Sayre DF. Distribution of metanephrine and normetanephrine in various animals and their analysis in diverse biological material. J Pharmacol Exp Ther 1966;153:15-29.

4 Da Prada M, Zurcher G. Simultaneous radioenzymatic determination of plasma and tissue adrenaline, noradrenaline and dopamine within the femtomole range. Life Sci 1976;19:1161-74.

5 Plouin P-F, Degoulet P, Tugaye A, Ducrocq M-B, Menard J. Le depistage du pheochromcytome: chez quels hypertendus? Etude semiologique chez 2585 hypertendus dont 11 ayant un pheocyromocytome. Nouv Presse Med 1981;10:869-72.

6 Wallace JM, Gill DP. Prazosin in the diagnosis and treatment of pheochromocytoma. JAMA 1978;240:2752-3.

7 Schütz $W$, Vogel E. Pheochromocytoma of the urinary bladder. A case report and review of the literature. Urol Int 1984;39:250-5.

8 Ackery DM, Tippett PA, Condon BR, Sutton HE, Wyeth P. New approach to the localisation of phaeochromocytoma: imaging with iodine-131-meta-iodobenzylguanidine. $\mathrm{Br}$ Med J 1984;288:1587-91.

9 Brown MJ, Allison DJ, Jenner DA, Lewis PJ, Dollery CT Increased sensitivity and accuracy of phaeochromocytoma diagnosis achieved by the use of plasma-adrenaline estimations and a pentolinium-suppression test. Lancet 1981;i:174-7.

10 Newsome HH Jr. The lack of normal catecholamine responses in patients with pheochromocytomas. Surgery 1983;94: 932-7.

11 Bravo EL, Tarazi RC, Fouad FN, Vidt DG, Gifford RW Jr. Clonidine suppression test. A useful aid in the diagnosis of pheochromocy toma. $N$ Engl J Med 1981;305:623-6.

12 Brown MJ, Allison DJ. Apologia for older techniques for localising phaeochromocytoma [Letter]. Lancet 1984;ii:1274.

13 Meyer JS, Stoica E, Pascu I, Shimazu K, Hartmann A. Catecholamine concentrations in CSF and plasma of patients with cerebral infarction and haemorrhage. Brain 1973;96:277-88.

14 Stoica E, Enulescu O, Caloinescu C. Catecholamine urinary excretion in cerebrovascular accidents. Neurol Psychiatr (Bucur) 1977;15:271-9. 